\title{
Personal Dosimetry Enhancement for Underground Workplaces
}

\author{
L. Thinová, A. Fronka, D. Milka
}

Personal dosimetry for underground workers mainly concerns measurement of the concentration of radon (and its daughters) and the correct application of the data in dose calculation, using a biokinetic model for lung dosimetry. A conservative approach for estimating the potential dose in caves (or underground) is based on solid state alpha track detector measurements. The obtained dataset is converted into an annual effective dose in agreement with the ICRP recommendations using the "cave factor", the value of which depends on the spectrum of aerosol particles, or on the proportional representation of the unattached and the attached fraction and on the equilibrium factor. The main difference between apartments and caves is the absence of aerosol sources, high humidity, low ventilation rate and the uneven surface in caves. A more precisely determined dose value would have a significant impact on radon remedies or on restricting the time workers stay underground. In order to determine how the effective dose is calculated, it is necessary to divide these areas into distinct categories by the following measuring procedures: continual radon measurement (to capture the differences in EERC between working hours and night-time, and also between daily and seasonal radon concentration variations); regular measurements of radon and its daughters to estimate the equilibrium factor and the presence of $218 \mathrm{Po}$; regular indoor air flow measurements to study the location of the radon supply and its transfer among individual areas of the cave; natural radioactive element content evaluation in subsoils and in water inside/outside, a study of the radon sources in the cave; aerosol particle-size spectrum measurements to determine the free fraction; monitoring the behaviour of guides and workers to record the actual time spent in the cave, in relation to the continuously monitored levels of Rn concentration.

Keywords: radon concentration, underground, cave, effective dose, aerosol particles.

\section{Introduction}

One of the more interesting type of underground spaces, in terms of personal dosimetry, are karst caves, which are found in regions with exceptionally high radon concentrations, (despite the very low uranium content in limestone) due to minimal airflow and negligible air exchange. Exact effective dose estimation is required, in view of the potential health hazards caused by inhaling radon and its daughters, in order to categorize such unsafe work areas. In this respect, the main differences between apartments and caves is the absence of aerosol sources (the aerosol concentration is approx. 100 times lower than in the outdoor atmosphere), high humidity, low ventilation rate and the uneven surfaces in caves. The conversion factor ( $\mathrm{m} S \mathrm{v} / \mathrm{WLM}$ ) is dependent on aerosol particle size spectrum resolution and on the distribution of radon daughters among the attached and unattached fraction [1]. With the aim of specifying the calculation of the real effective dose in caves, the following test measurements were carried out a few years ago: natural radioactive element content eval-

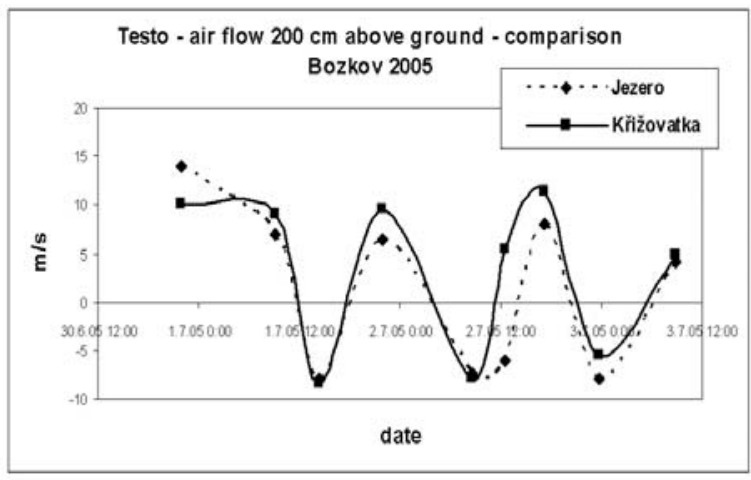

a) uation in subsoils and in water inside/outside to study radon sources in the cave; continual radon measurements; regular radon and daughters measurements using a sampling procedure to specify the proportion of radon daughters; regular indoor air flow measurements to study the location of the radon supply and its transfer among individual areas of the cave; 5-day aerosol particle-size spectrum measurements to determine the free fraction and to compare the aerosol spectra in an apartment and in a cave; comparative measurements using various radon and daughters monitors to study their behaviour in an area with high humidity (including Radim 4 - a device for simultaneous detection of radon concentration and concentration of unattached and attached fractions of its daughters); monitoring the behaviour of guides and visitors to record time spent in the cave, related to the continuously monitored levels of $\mathrm{Rn}$ concentration; some personal monitors for testing the detection of radon and its daughters. All of the obtained data was used for a discussion of the location-related value of "cave factor" and consequently for effective dose calculation.

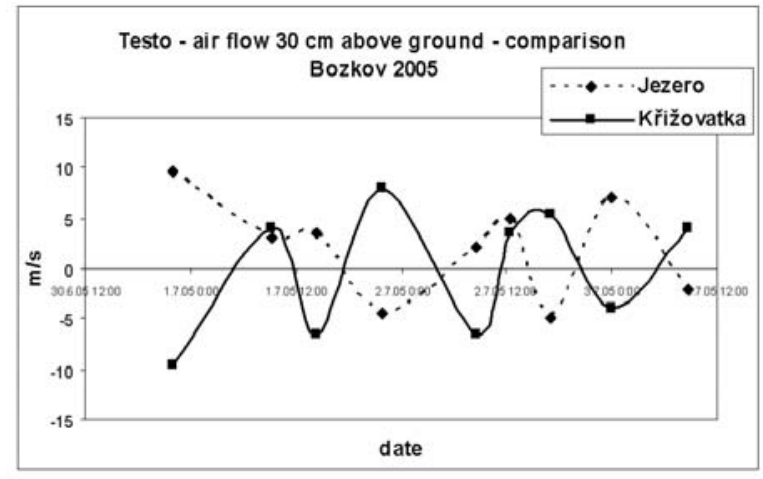

b)

Fig. 1: Air flow $200 \mathrm{~cm} \mathrm{(a)} \mathrm{and} 30 \mathrm{~cm} \mathrm{(b)} \mathrm{above} \mathrm{ground} \mathrm{in} \mathrm{two} \mathrm{places} \mathrm{connected} \mathrm{by} \mathrm{a} \mathrm{tunnel} \mathrm{and} \mathrm{stairs}$ 


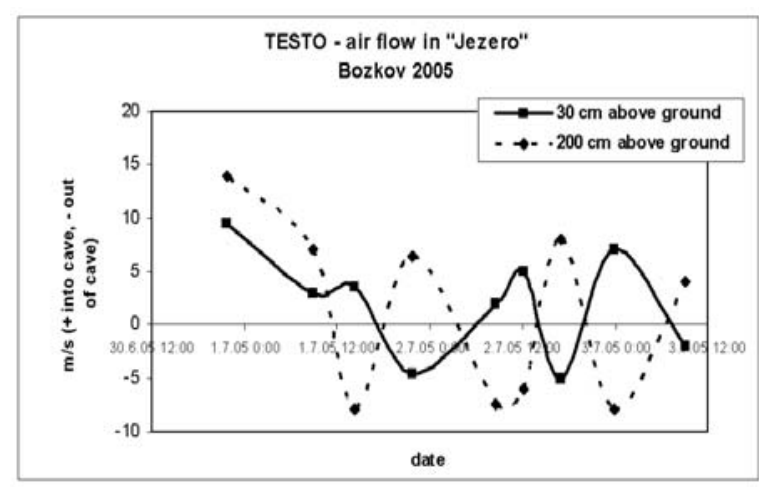

a)

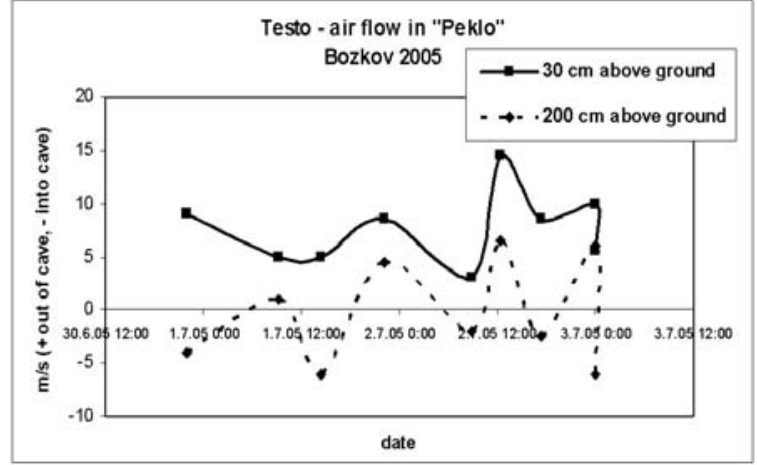

b)

Fig. 2: The different systems of air flow in the "Jezero" (a) and "Peklo" (b) caves

\section{Some results of the air flow measurements}

Individual segments of underground areas are interconnected to each other in dependence on their contacts with the earth surface (through crevasses) and external atmosphere conditions - pressure and temperature (the so called "summer and winter" mode). The air flow is affected by the movement of visitors in the cave, of course. (The tendency to protect the conservative microclimate of caves by constructing double doors results in an increase in radon concentration). Air flow measurements give very interesting information about the origin of "radon pockets" with very high radon concentration, and enable a study of the location of the radon supply and its transfer among individual areas of the cave. Some results of air flow measurements using the TESTO device are shown in Figs. 1, 2.

\section{Continual radon monitoring}

Comparative measurements were carried out using various radon and daughters monitors to study their behaviour in area with high humidity (including Radim 4 - a device

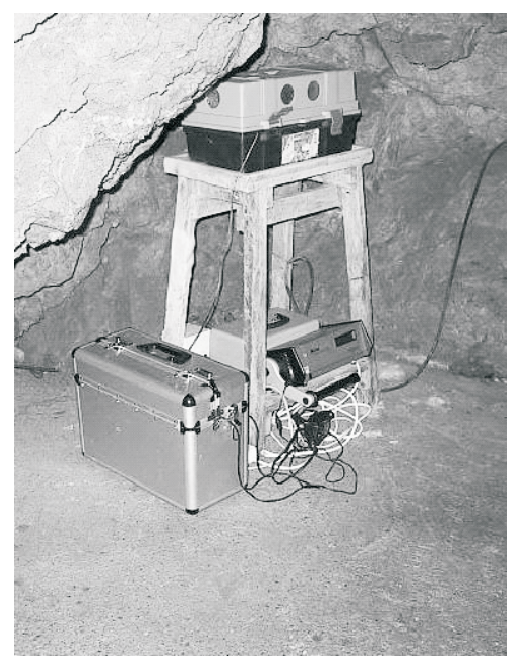

Fig. 3: Radim 3 continual radon monitor in a plastic box with dessiccant, AlphaGuard continual radon monitor, Fritra 4 continual radon and attached and unattached radon daughters fraction monitor for simultaneous measurement of radon concentration and concentration of unattached and attached fraction of its daughters).

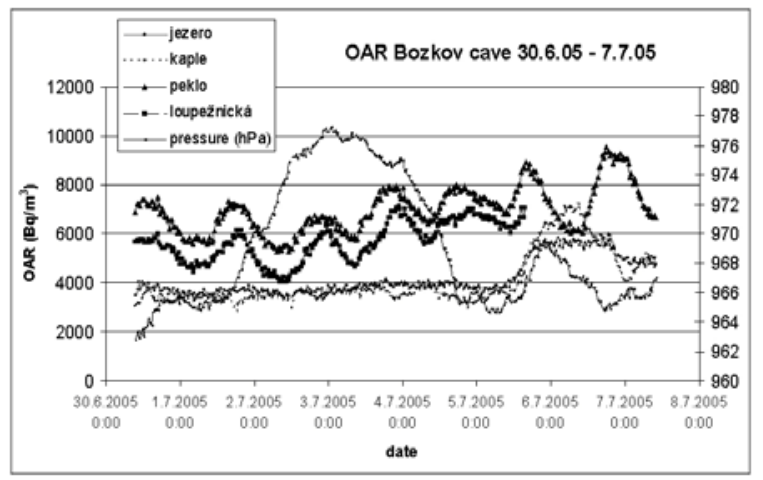

Fig. 4: Radon concentration in different places in a cave (Radim 3)

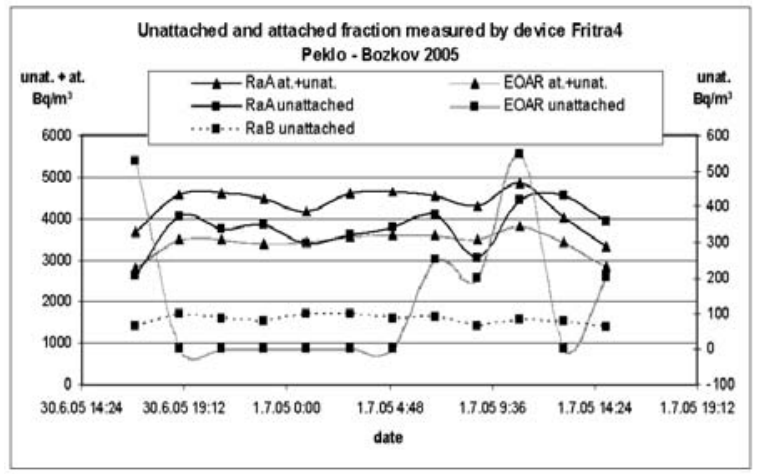

Fig. 5: Some results of measurement using Fritra 4

Most of the results of the continual radon, radon daughters and unattached fraction measurements show the equilibrium factor around $\mathrm{F}=0.5$ and the unattached fraction around $2 \%$. Note: One of the most important question remains: how accurately was the unattached fraction measured?

\section{Effective dose calculation in caves}

With regard to the standard monitoring procedure for radon and its daughters, routinely used in the Czech Repub- 
lic, two sets (summer and winter) of solid state alpha-track detectors are placed inside the cave. The results (equilibrium equivalent radon concentration-EERC) are converted into the equivalent dose, including the application of a special cave-evaluation methodology which includes additional factors (e.g. differences between the unattached fraction and the comparison with common indoor atmosphere) in order to avoid underestimating the real dose. Based on the ICRP 60 recommendation, the calculation used the equation:

$$
\mathrm{E}(\mathrm{mSv})=h_{p} \cdot a \cdot T(\mathrm{~h}) \cdot \operatorname{EERC}\left(\mathrm{Bq} \cdot \mathrm{m}^{-3}\right),
$$

$T \quad$ working time,

EERC equilibrium equivalent radon concentration,

a conversion factor

$h_{p} \quad$ "cave factor" $=1.5$

The new approach presumes that the entire effective dose that a person receives from radon daughters should be calculated as the sum of all effective doses obtained from the individual sizes of the aerosols (including the unattached fraction), using the following assumptions: only ${ }^{222} \mathrm{Rn}$ and its daughters occur in the caves (if this assumption is incorrect, it would be difficult to determine the conversion factors between the exposure to products of radon decay (WLM) a EERC, because the radon daughters are differentiated by their latency energy); the mutual ratio of radon daughters and the equilibrium factor and the spectrum of aerosols in a given place is constant [2]. The calculation will use the respiratory tract model [3].

\section{Aerosol measurement campaign}

In addition to the radon measurements, the aerosol particle size distribution was also measured, as one of the most important parameters for dose evaluation (diffusion battery and differential mobility analyzer, aerosol impactor). It was found that the presence of aerosol particles $1-10 \mu \mathrm{m}$ in diameter is definitely caused by the presence of visitors or personnel; when the cave was closed, the particles disappeared quickly in the play out process (after approx. $1 \mathrm{~h}$ the concentration was about $10-4$ segments $\left.\mathrm{cm}^{-3}\right)$. On the other hand, the concentration of particles about $200 \mathrm{~nm}$ in diameter is relatively stable $\left(\sim 10\right.$ segments $\left.\mathrm{cm}^{-3}\right)$. For the last particle size group $(\sim 10 \mathrm{~nm})$, it seems that the aerosols are produced by intensive work or movement (the concentration is about $100-1000$ segments $\mathrm{cm}^{-3}$ ). The aerosol spectrum plays an important role in the recently suggested dose calculation (see Fig. 6 and Fig. 7 below).

\section{Conclusions}

The enhancement of personal dosimetry for underground work places includes a study of the given questions from three main points of view:

1. A classification of underground areas, and of the main characteristics and differences that have an influence on individual irradiation from radon (or from other sources of radiation) and on measuring the concentration of radon and radon daughters (specification of radon sources, remediation or other method for eliminating radon sources)

2. Summation and a critical evaluation of approaches to the evaluation of lung irradiation, determination of the input parameters for evaluation of individual irradiation (with the use the latest information from NRPB)

3. Selection of the correct measurement method (equipment) leading to the real value of the chosen parameters (see point 2), providing sufficiently clear information

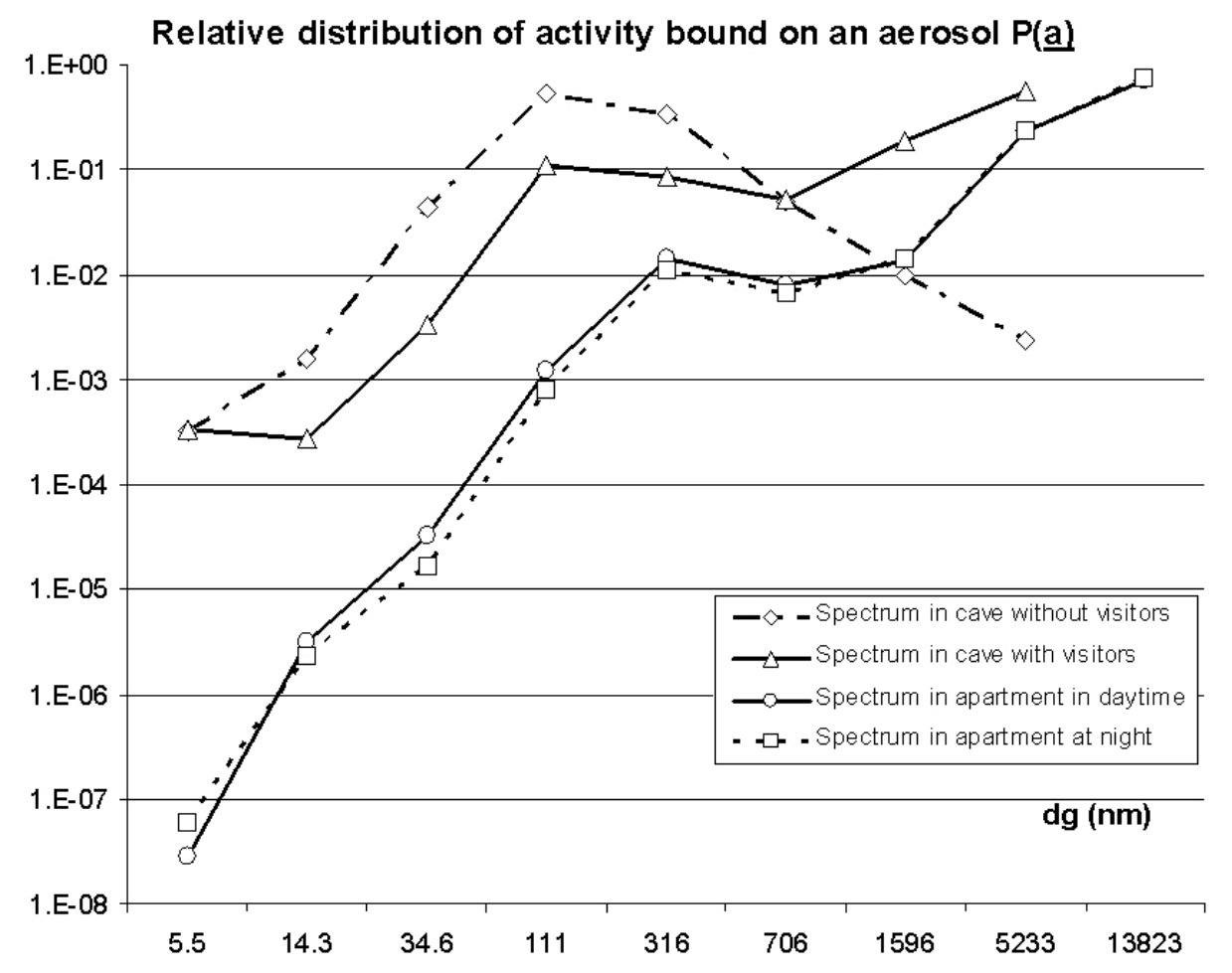

Fig. 6 


\section{The trend of radon-to-dose conversion factors for a cave and for an apartment}

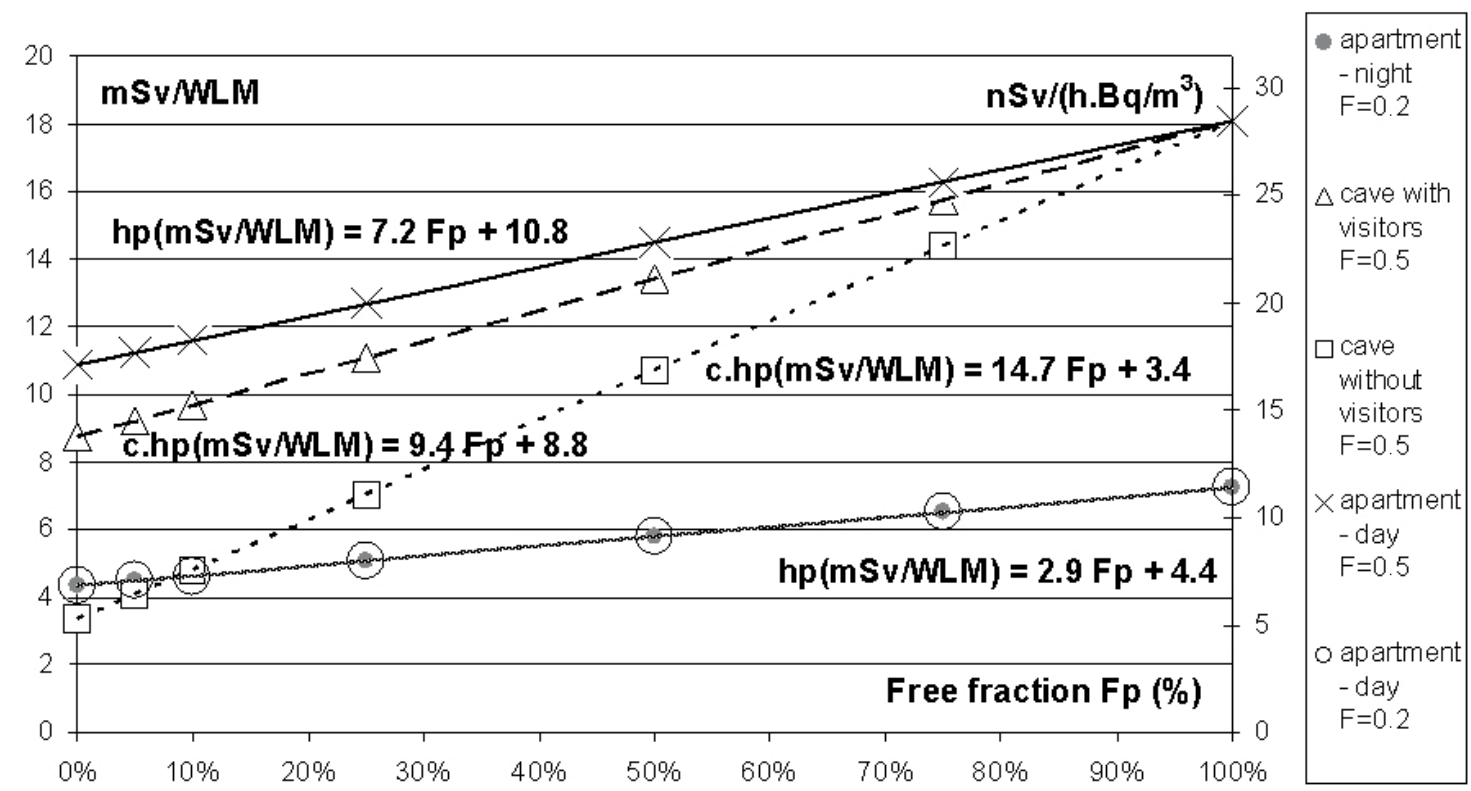

Fig. 7

about the concentration of radon and its daughters within various types of underground areas (and segments of areas), assessing information about aerosol spectra suitable for determining the unattached fraction.

The aim of the research will be to elaborate a new methodology, for calculating the effective dose for guides in caves that are visited by people or used for speleotherapy, and applicable for other underground spaces. The existing measurements and a follow-up survey will be used.

The existing results indicate that individual underground spaces have markedly different radon concentrations and representations of the unattached fraction. These factors have a substantial impact on dose calculation. The results from the group of evaluated caves did not confirm the presence of aerosol sources, or other sources of radon, apart from attendee rock (possibly water); high radon concentrations are accompanied by a very low flow rate; the equilibrium factor varies mostly between $0.2-0.5$; the unattached fraction constituted approximately $2 \%$. We have not yet been able to determine with certainty the ratio of the attached and unattached fraction, which could significantly influence the calculations. The time spent underground by guides should be related to the actual radon concentration at a given time. Personal dosimeters are advised. All results should be used as input parameters for calculating the LUDEP dose-in-lungs model. Using the method described above the effective dose can be recalculated fairly precisely.

\section{References}

[1] ICRP. Protection against Radon-222 at Home and at Work. ICRP Publication 65. Pergamon Press, Oxford, UK, 1993.

[2] Hihds, W. C.: Aerosol Technology, Properties, Behavior, and Measurement of Aerosol Particles. Second edition. John Witney \& Sons, New York, 1998.

[3] Birchall, A. at al.: Respiratory track model. NRPB-SR287. Chilton. Didcot. Oxon OX11 0RQ. 1996.

RNDr. Lenka Thinová

e-mail: thinova@fjfi.cvut.cz

Czech Technical University in Prague

Faculty of Nuclear Sciences and Physical Engineering, Břehová 7

11519 Prague 1, Czech Republic

\section{A. Fronka}

National Radiation Protection Institute

Bartoškova 28

14000 Prague 4, Czech Republic

Mgr. Dušan Milka

Bozkov Dolomite Cave Direction 51213 Bozkov, Czech Republic 